Section of Psychological Cybernetics and Psychobiology, Institute of Psychology I (Head: Prof. Dr. K. Th. Kalveram), University of Düsseldorf/F.R.G.

\title{
Influence of Bleeding Order on Plasma Corticosterone Concentration in the Mouse
}

\author{
J. Kugler, K. W. Lange and K. Th. Kalveram \\ With 1 Figure
}

Summary. The influence of the order of bleeding on corticosterone release in the mouse was examined. Female C57/BL6 mice were housed in groups of five animals in a low noise environment. After 10 days, they were successively captured and sacrificed every 2 minutes. The corticosterone levels increased in the fourth and fifth mice in a cage, i.e. within the time intervals from 4 to 6 minutes and from 6 to 8 minutes after the capture of the first animal. These results suggest that quiescent corticosterone levels can be measured only when the blood samples are obtained within 4 minutes following the capture of the first mouse.

Key words: Corticosterone - Bleeding procedure - Mouse - Stress

\section{Introduction}

Over the last decades, the relationship between experimentally induced stress and corticosterone release has been widely demonstrated (Selye, 1982). Less attention has been paid to the effects of non-experimental laboratory procedures on animals. Fortier (1958) demonstrated that changes in the laboratory environment can cause substantial rises in plasma free corticosteroids. The present study was undertaken to examine whether the capture of mice influences the corticosterone levels in the mice that perceive the "attack" of the experimenter.

\section{Material and Methods}

Twenty female C57/BL6 mice at the age of 10 weeks were housed in groups of five animals. Each cage was separately kept in a low noise environment for 10 days. The mice were maintained on a 12-hour light: 12-hour dark cycle. On day 11, the mice were randomly captured and decapitated one after another every 120 seconds. Blood samples were heparinized, cooled at $4^{\circ} \mathrm{C}$, centrifuged, and frozen at $-18^{\circ} \mathrm{C}$. Plasma corticosterone was determined using radioimmunoassays (Radioassay Systems Laboratories, Carson, California). 


\section{Results}

As presented in Fig. 1, the order of bleeding has a significant effect on the plasma corticosterone level (ANOVA, F-test, $\mathrm{p}<0.05$ ). The first three animals removed from a cage did not differ markedly in their corticosterone concentrations. In comparison with the first three mice, the corticosterone levels in the fourth and fifth mice exhibited a two- to threefold increase in plasma corticosterone concentration.

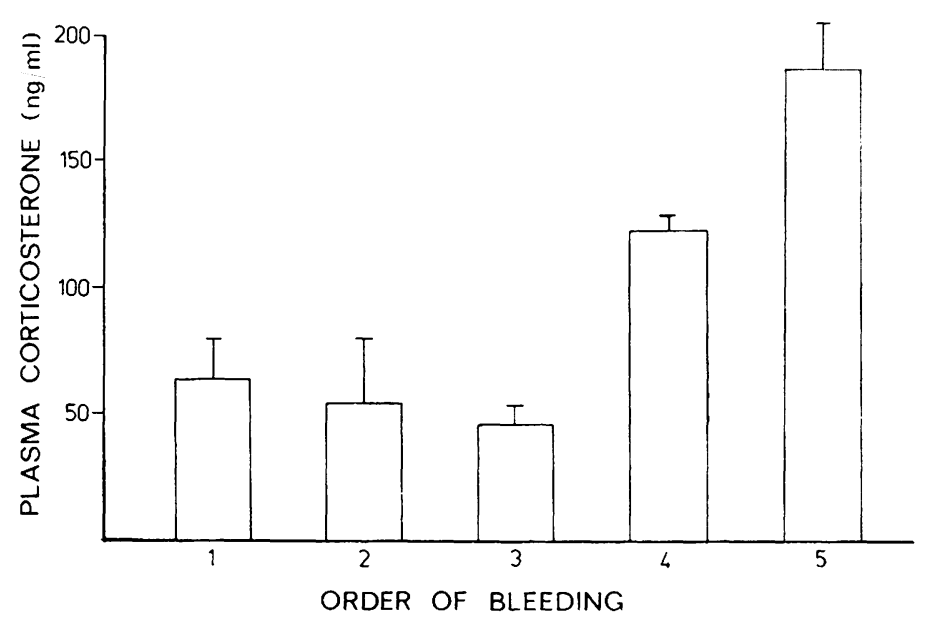

Fig. 1 Influence of bleeding order on plasma corticosterone concentration. Mean values and standard errors of the mean are presented

\section{Discussion}

The present study demonstrates the influence of the order of bleeding on the plasma concentration of corticosterone in mice. The results suggest that the increase in corticosterone concentrations takes place in the fourth and fifth mice in a cage, i.e. within the time intervals from 4 to 6 minutes and from 6 to 8 minutes after the capture of the first animal. This partly confirms results of Riley and coworkers (1982) who demonstrate that quiescent corticosterone levels can be obtained only when the blood samples are drawn within $31 / 2$ minutes following removal of the mice from protective storage. This indicates that blood obtaining procedures have to be finished within the time interval from $31 / 2$ to 6 minutes in order to avoid procedure-induced artefacts. The difference between the two observed time-lags until the corticosterone release is stimulated may be due to various factors, like the number of animals in a cage, the strain, or the procedure to obtain blood. It can be supposed that the animals left in the cage perceive the capture of their cage mates as a predatory attack. It can be concluded that the order of bleeding or the time taken by the bleeding procedure have to be controlled in order to reduce the error variance that may mask experimentally inducerl effects.

Acknowledgement. The authors are grateful to Professor H. Bojar (Department of Oncological Chemistry, University of Düsseldorf) for his support. 


\section{References}

[1] Fontier, C.: Sensitivity of the plasma free corticosteroid response to environmental change in the rat. Arch. Int. Physiol. 66 (1958) 672-673.

[.?] Riley, V.; Fitzmaurice, M. A.; Spackman, D. H.: Psychoneuroimmunological factors in neoplasia. In: Psychoneuroimmunology. Auer, R. (ed.). Orlando: Academic Press 1981.

[3] Selye, H.: History and Present Status of the Stress Concept. In: Handbook of Stress. GoldBerger, L.; Breznitz, S. (eds.). New York: The Free Press 198.2.

(Accepted 1 September 1987)

Author's address: Dr. J. Kugler, Psychologisches Institut I, Universität Düsseldorf, Universitätsstr. 1, D-4000 Düsseldorf 1 